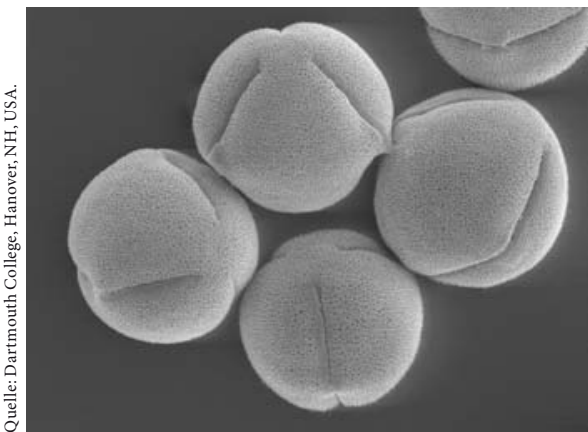

\section{Rekombinante Allergene zeigen in Schweizer Phase-I-Studie Wirkung}

Mit einem rekombinanten Allergen wollen Schweizer Wissenschafter Patienten mit Katzenallergie unempfindlich machen. Der Vorteil sind eine hohe Wirksamkeit und eine geringe Behandlungsdauer, wie eine jetzt beendete Phase-I-Studie zeigt. Allerdings fehlt Geld für eine Phase-II-Studie.

Eine Forschungsgruppe am Schweizer Institut für Allergie- und Asthmaforschung (SIAF) in Davos hat einen neuen Weg der Desensibilisierung eingeschlagen. Sie benutzt ein rekombinantes Allergen und injiziert es direkt in einen Lymphknoten. «Die Ergebnisse einer Phase-I-Studie, die jetzt abgeschlossen wurde, sind sehr ermutigend», sagt Professor Reto Crameri vom SIAF, das zur Universität Zürich gehört.

\section{Erfolgreiche Tierversuche}

Crameris Gruppe hat nach erfolgreichen Versuchen an Mäusen und an Zellkulturen eine Phase-I-Studie durchgeführt, bei der ein Allergen getestet wurde, das gegen die Katzenallergie unempfindlich machen soll. Ein Placebo erhielten 8 Patienten; 12 Patienten wurde das rekombinante Allergen verabreicht. Es wurde dreimal direkt in Lymphknoten gespritzt - nach der ersten Behandlung noch einmal nach 6 bzw. nach 8 Wochen. Um die Wirksamkeit zu überprüfen, wurden die Probanden mit einem «Katzenextrakt» in der Nasenhöhle und in den Augen gereizt. Dabei zeigte sich, dass die Allergiker, die mit dem rekombinanten Allergen behandelt waren, gegenüber der Reizung wesentlich toleranter reagierten als diejenigen, die das Placebo bekommen hatten.

Crameri führt den Erfolg der Behandlung vor allem auf zwei Faktoren zurück: auf das rekombinante Aller- gen und auf die Injektion direkt in einen Lymphknoten. Mit seiner Forschungsgruppe hat er die molekulare Sequenz an den Proteinen identifiziert, an die beim Allergiker die IgE-Antikörper ankoppeln. Binden sich IgEAntikörper an ein Allergen, wird die ganze Kaskade der Immunantwort ausgelöst, die schliesslich zum Auftreten der Allergien mit ihren Symptomen führt. Mit biotechnologischen Verfahren haben die Davoser Forscher ein Protein hergestellt, dem die Sequenz fehlt, an dem das IgE binden kann. Das Immunsystem kann auf das Allergen nicht mehr reagieren. «Der Körper gewöhnt sich dann an die Präsenz eines harmlosen Allergens», sagt Crameri. Wenn er nach Abschluss der Desensibilisierung mit einem «richtigen» Allergen in Berührung kommt, toleriert er es und die allergische Reaktion bleibt aus.

\section{Bessere Compliance}

«Ein grosser Vorteil unserer Methode ist die relativ kurze Behandlungsdauer von 8 Wochen», sagt der Wissenschafter. Bei der herkömmlichen Therapie geht die Compliance der Patienten immer mehr zurück, desto länger sie dauert. Bei 3 Injektionen über 8 Wochen verteilt werden wohl relativ wenige Patienten «zwischendurch» aussteigen. «Das Besondere an unserem Ansatz ist, dass wir das Allergen direkt in einen Lymphknoten injizieren", sagt Crameri. Deshalb ist für die
Desensibilisierung mit den rekombinanten Allergenen aus Davos eine wesentlich geringere Konzentration des Wirkstoffs notwendig. In einen Lymphknoten gespritzt, ist es dort den Zellen des Immunsystems direkt ausgesetzt. «Es reicht eine um ein Hundertstel bzw. ein Tausendstel geringere Dosierung», stellt Crameri fest. Derzeit arbeiten seine Mitarbeiter und er noch an rekombinanten Allergenen, die bei einer Birkenpollen- bzw. einer Hausstauballergie eingesetzt werden können.

\section{Geld für Forschung fehlt}

So ermutigend die Ergebnisse für die etwa 2,3 Millionen Allergiker in der Schweiz auch sein mögen, so schlecht stehen im Moment die Aussichten, dass die Forschung in Richtung auf einen klinischen Einsatz weitergeführt werden kann. Nach dem erfolgreichen Abschluss der Phase-I-Studie müsste nun eine Phase-II-Studie folgen, die international durchgeführt und durch die Ergebnisse in mehreren Zentren abgestützt werden muss. An etwa 150 Allergikern müsste die Desensibilisierung mit dem rekombinanten Allergen durchgeführt werden. Das allerdings bedeutet eine Investition in Millionenhöhe. Im Moment fehlt es an einem Investor, der den Fortgang der klinischen Erprobung finanziert. «Die Venture Capitalists halten sich im Augenblick ziemlich stark zurück», sagt Crameri. (rfi)

\section{KARGER}

Fax +49761 4520714 